\title{
IDENTIFIKASI SPERMA SAPI NORMAL DAN ABNORMAL MENGGUNAKAN ALGORITMA JARINGAN SARAF TIRUAN
}

\author{
Endi Permata \\ Universitas Sultan Ageng Tirtayasa \\ Email: endipermata@untirta.ac.id \\ Ri Munarto \\ Universitas Sultan Ageng Tirtayasa \\ Email: rim_munarto@yahoo.com \\ Geovani Orlando \\ Universitas Sultan Ageng Tirtayasa \\ Email: geovaniorlando@gmail.com
}

\begin{abstract}
ABSTRAK
Analisis spermatozoa normal dan abnormal telah dilakukan berdasarkan fitur ukuran, yaitu panjang dan lebar kepala, leher serta panjang ekor. Namun, spermatozoa normal dan abnormal juga tergantung pada bentuknya. Oleh karena itu, Penelitian ini bertujuan mengidentiffikasi sperma sapi normal dan abnormal menggunakan algoritma jaringaan saraf tiruan berdasarkan fitur bentuk. Objek penelitian adalah citra sperma sapi yang didapatkan dari website University of Wisconsin-Madison departemen of animal sciences Amerika Serikat yang terdiri dari 30 citra sperma sapi normal dan 30 citra sperma sapi abnormal. Metode segmentasi citra untuk memisahkan spermatozoa dari latarnya. Mendapatkan deteksi tepi menggunakan metode pendeteksi tepi Canny. Tepi Canny ini merupakan tahap awal dalam pengkodean rantai menggunakan metode freeman chain code. Kode rantai digunakan untuk mendapatkan ekstraksi fitur denga Elliptical Fourier Descriptor yang berkaitan dengan koefisien harmonik fourier ke- $n$ yaitu $a_{n}$, $b_{n}, c_{n}$ dan $d_{n}$. Koefisien harmonik fourier ini digunakan untuk identifikasi sperma sapi normal dan abnormal menggunakan algoritma jaringan saraf tiruan. Hasil identifikasi dari tiga kali pengujian yang dilakukan menunjukan akurasi terbaik pada harmonik fourier sama dengan $6(\mathrm{~N}=6)$, yaitu sebesar $80 \%$ dengan demikian fitur bentuk dapat digunakan untuk mengidentifikasi sperma sapi norma dan abnormal.
\end{abstract}

Kata kunci: sperma sapi, elliptical fourier descriptor, kode rantai, jaringan saraf tiruan.

\section{ABSTRACT}

An analysis of normal and abnormal of spermatozoa has been done based on feature sizes that are the length and width of the head, mid-piece and the length of the tail. However, normal and abnormal spermatozoa are also depending on the form. Therefore, this study aimed to identification normal and abnormal sperm of bulls using algorithm artificial neural network based on shape features. The object of research is the image of a bull sperm obtained from the website of the University of Wisconsin-Madison department of animal sciences United States, which consists of 30 images of a bull sperm normal and 30 images of a bull sperm abnormal. Image segmentation method is to separate the sperm from the background. Getting the edge detection by using Canny edge detection method. Canny edge is an early stage in the chain coding by using chain freeman code method. Chain code is used to get the premises feature extraction Elliptical Fourier Descriptor associated with harmonic fourier coefficients to-n namely $a_{n}, b_{n}, c_{n}$ dan $d_{n}$. Harmonic fourier coefficients are used for the identification of normal and abnormal sperm bull by using algorithm artificial neural network. The identification results of three tests performed showed the best accuracy on Fourier harmonic is equal to $6(N=6)$, amounting to $80 \%$ thereby shape feature can be used to identification the bull normal and abnormal sperm.

Keywords: sperm bull, elliptical fourier descriptor, chain code, atificial neural network.

\section{PENDAHULUAN}

Perkembangan teknologi di bidang reproduksi ternak terus dilakukan demi menyempurnakan dan meningkatkan produktivitas ternak yang mempunyai potensi besar dalam penyediaan daging. Namun, 
dengan kelainan spermatozoa sapi terutama berdasarkan kondisi morfologi yang masih masalah penting karena kondisi morfologi yang berhubungan dengan kualitas spermatozoa sapi terutama untuk program inseminasi buatan untuk kedua daging sapi dan susu industri. Kualitas sperma dapat ditentukan oleh beberapa kriteria, seperti ukuran dan bentuk (morfologi) dari kepala, panjang dan bentuk ekor dan perilakunya gerakan (motilitas). Spermatozoa terdiri dari dua bagian fungsional penting, kepala dan ekor [1]. Spermatozoa pada umumnya diukur dari segi fitur morfologi berikut kepala sperma, daerah kepala, perimeter, lebar, panjang, rasio lebar-panjang, dan sebagainya [2]. Parameter penting dinilai selama analisis spermatozoa adalah morfologi keseluruhan, atau bentuk spermatozoa.

Di laboratorium analisis spermatozoa ditentukan secara acak dalam setiap wadah yang diletakan di meja mikroskop. Setiap informasi diperoleh jumlah tertentu spermatozoa normal dan abnormal secara acak, sehingga diperoleh informasi persentase spermatozoa normal dan abnormal dari setiap sediaan sampel. Metode konvensional ini akan menimbulkan perbedaan hasil pengukuran jika dilakukan oleh ahli yang berbeda, karena perhitungan spermatozoa normal dan abnormal dilakukan secara acak [3]. Setiap sperma muncul pada akan diklasifikasikan dan dihitung ke dalam kelas yang berbeda. [4]. Abbiramy dan Shanthi dalam penelitiannya mengembangkan segmentasi spermatozoa dan analisis parameter morfologi berdasarkan deteksi Teratozoospermia [5]. Segmentasi dilakukan melalui dua tahapan yaitu deteksi sel dan pembagian spermatozoa kedalam bagian-bagian tertentu seperti, area kepala, perimeter, panjang kepala, lebar kepala, panjang leher, dan panjang ekor. Hasil penelitian ini adalah berupa fitur spermatozoa normal dan abnormal berdasarkan ukuran sebagaimana yang telah disebutkan sebelumnya.

Penelitian ini mencoba mengimplementasikan jaringan saraf tiruan untuk identifikasi sperma sapi ke dalam dua kelas, yaitu normal dan abnormal dengan menggunakan algoritma jaringan syaraf tiruan Backpropagation. Citra yang digunakan dalam penelitian ini berasal dari website University of Wisconsin-Madison departemen of animal sciences Amerika Serikat. Terdapat 60 citra sperma sapi yang cropping secara manual terdiri dari 30 citra normal dan 30 abnormal. Citra sperma sapi yang didapatkan selanjutnya dilakukan segmentasi untuk mendapatkan tepi menggunkan operator tepi canny. Selanjutnya dilanjutkan dengan pengkodean rantai menggunaakan Freeman chain code. Ekstraksi fitur menggunakan Elliptical Fourier Descriptor dengan mengambil koefisen fourier berserta harmoniknya yaitu $a_{n}, b_{n}, c_{n}$ dan $d_{n}$. Matrik fitur selanjutnya diidentifikasi menggunakan jaringan saraf tiruan Backpropagation dengan ketentuan data digunakan 40 training dan 20 testing, dengan demikian sistem yang dibangun dapat melakukan identifikasi sperma sapi dengan baik.

\section{METODOLOGI PENELITIAN}

Diagram dari metode yang digunakan dalam penelitian ini ditunjukkan seperti pada Gambar 1.

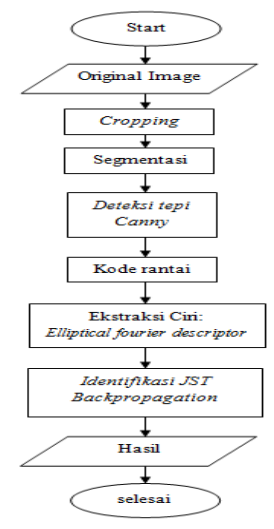

Gambar 1. Diagram penelitian

\subsection{Data}

Data yang digunakan dalam penelitian ini adalah citra sperma sapi dari University of WisconsinMadison departemen of animal sciences Amerika Serikat. Jumlah citra sperma sapi adalah 30 sperma sapi normal dan 30 sperma sapi abnormal.

\subsection{Kode Rantai}

Pengkodean rantai dimulai dari hasil pendeteksian tepi. Pengkodean ini berdasarkan pada Freeman pada kontur tertutup. Menurut deskripsi Freeman (Khul, 1982), sebuah kontur tertutup dapat dikodekan 
dengan 8 garis standar pada matriks $3 \times 3$ dimana elemen pusatnya adalah kaki garis dan ujungnya diberikan oleh satu elemen pada matriks seperti yang ditunjukkan pada Gambar 2.

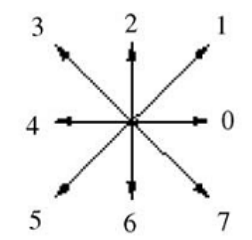

\section{Gambar 2. Pengkodean rantai}

Gambar 2 menunjukkan vektor arah pengkodean rantai dari tepi citra yang dapat direpresentasikan dalam bentuk kode angka antara 0 hingga 7. Masing-masing angka mewakili arah yang berbeda menyerupai arah mata angin. Dengan menggunakan pengkodean Freeman, sebuah kontur tertutup dapat digambarkan sebagai rantai.

$c=u_{1} u_{2} u_{3} u_{4} \ldots . . . u_{k}$

dimana $u \in\{0,1,2, \ldots, 7\}$ merupakan vektor dengan arah $(\pi / 4) u$. Panjang masing-masing $u$ akan sama dengan 1 jika genap atau $\sqrt{2}$ jika ganjil. Misalkan $u$ adalah elemen dari rantai Freeman, maka panjang $(\Delta t)$ dari rantai tersebut adalah:

$\left|u_{i}\right|=\Delta t=1+\left(\frac{\sqrt{2}-1}{2}\right)\left(1-(-1)^{u_{i}}\right)$

Sehingga jika $p$ adalah banyaknya elemen pada rantai dari keseluruhan kontur, maka panjang rantai akan menjadi :

$t_{p}=\sum_{i=1}^{p} \Delta t_{i}$

\subsection{Elliptical Fourier Descriptor}

Tujuan utama dari analisis Elliptical Fourier Descriptor adalah mengaproksimasi edge tertutup sebagai jumlah harmonik eliptik. Untuk setiap harmonik dapat digunakan 4 koefisien Fourier $a_{n}, b_{n}, c_{n}$ dan $d_{n 1}$, sedangkan untuk mengidentifikasi kontur tertutup $K$ elemen dapat diperoleh dengan menggunakan $N$ harmonik. Koefisien Fourier $a_{n}, b_{n}, c_{n}$ dan $d_{n}$ dan diberikan oleh :

$$
\begin{aligned}
& a_{n}=\frac{T}{2 n^{2} \pi^{2}} \sum_{P=1}^{K} \frac{\Delta x_{p}}{\Delta t_{p}}\left[\cos \frac{2 n \pi t_{p}}{T}-\cos \frac{2 n \pi t_{p-1}}{T}\right] \\
& b_{n}=\frac{T}{2 n^{2} \pi^{2}} \sum_{P=1}^{K} \frac{\Delta x_{p}}{\Delta t_{p}}\left[\sin \frac{2 n \pi t_{p}}{T}-\sin \frac{2 n \pi t_{p-1}}{T}\right] \\
& c_{n}=\frac{T}{2 n^{2} \pi^{2}} \sum_{P=1}^{K} \frac{\Delta y_{p}}{\Delta t_{p}}\left[\cos \frac{2 n \pi t_{p}}{T}-\cos \frac{2 n \pi t_{p-1}}{T}\right] \\
& d_{n}=\frac{T}{2 n^{2} \pi^{2}} \sum_{P=1}^{K} \frac{\Delta y_{p}}{\Delta t_{p}}\left[\sin \frac{2 n \pi t_{p}}{T}-\sin \frac{2 n \pi t_{p-1}}{T}\right]
\end{aligned}
$$

Koefisien Fourier $a_{n}, b_{n}, c_{n}$ dan $d_{n}$ dari pendekatan Fourier pada kontur tertutup digunakan sebagai klasifikasi kontur. Sifat-sifat bentuk kontur harus dispesifikasikan sebab koefisien yang dihasilkan beragam menurut titik awal penelusuran kontur dan rotasi spasial, besaran, translasi kontur serta prosedur normalisasi.

\subsection{Jaringan Saraf Tiruan Backpropagation}

Backpropagation merupakan algoritma pembelajaran yang terawasi dan biasanya digunakan oleh perceptron dengan banyak lapisan untuk mengubah bobot-bobot yang terhubung dengan neuron-neuran yang ada pada lapisan tersembunyinya. Algoritma backpropagation menggunakan error output untuk 
mengubah nilai bobot-bobotnya dalam arah mundur (backward). Untuk mendapatkan error ini, tahap perambatan maju (forward propagation) harus dikerjakan terlebih dahulu. Pada saat perambatan maju, neuron-neuron diaktifkan dengan menggunakan fungsi aktivasi sigmoid.

Prinsip kerja dari algoritma backpropagation adalah sebagai berikut, pada saat proses umpan maju, neuron pada input layer akan mengirimkan informasi ke setiap neuron pada hidden layer. Neuron hidden layer ini akan melakukan proses komputasi terhadap informasi yang diterima dan menghasilkan output yang berasal dari fungsi aktivasinya. Selanjutnya output dari hidden layer tersebut akan dikirimkan lagi ke lapisan berikutnya, yang dalam hal ini adalah output layer. Didalam output layer ini berlangsung proses yang sama seperti pada hidden layer. Namun, output dari hasil aktivasi output layer ini akan digunakan sebagai sinyal respon dari JST. Sinyal respon output JST ini akan dibandingkan dengan target yang diinginkan dan dihitung besar error (selisih antara output yang dihasilkan dengan target yang ingin dicapai). Error yang diperoleh ini dikirimkan kembali ke lapisan-lapisan sebelumnya dan kemudian digunakan untuk mengkoreksi dan mengubah bobot-bobot JST berdasarkan learning error yang diberikan pada JST tersebut.

\section{HASIL DAN PEMBAHASAN}

\subsection{Citra Masukan}

Data citra digunakan dalam penelian ini adalah dari website University of Wisconsin-Madison Departemen of Animal Sciences Amerika Serikat. Gambar 3 menunjukan citra asli sperma sapi di cropping secara manual sehingga didapatkan bentuk sperma sapi normal dan abnormal.

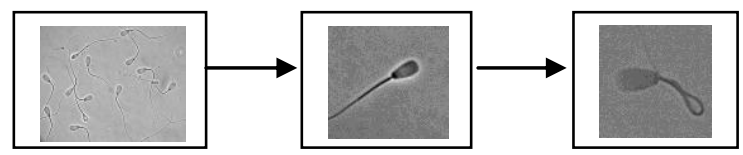

Gambar 3. Proses Citra Masukan

\subsection{Preprocessing}

Proses segmentasi citra untuk memisahkan antara background dengan objeknya. Selanjutnya pendetksian dalam penilitian ini digunakan pendeteksian tepi menggunakan operator Canny. Canny digunakan karena deteksi tepi yang optimal untuk mendapatkan hasil deteksi tepi halus.

Tahap selanjutnya yaitu pengkodean rantai dengan menggunaakan freeman chain code. Setiap piksel pada tepi objek diwakili oleh angka dari 0 hingga 7 yang didasarkan pada kode rantai freeman. Ditunjukan pada gambar 4.

\subsection{Ekstraksi Ciri}

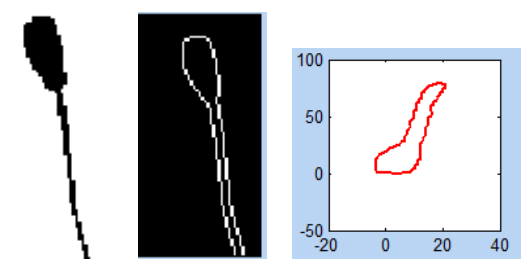

Gambar 4. Preprocesssing

Pada metode Elliptical Fourier Descriptor dengan menggunakan barisan angka-angka hasil chain code maka akan dihasilkan koefisien $a_{n}, b_{n}, c_{n}, d_{n}$. Setelah dinormalisasi akan didapatkan kembali koefisien Fourier. Normalisasi dibutuhkan agar hasil klasifikasi invarian terhadap ukuran, translasi dan rotasi.

Tabel 1 : Koefisien Fourier dengan N=6 dari Gambar 5

\begin{tabular}{cccc}
\hline $\boldsymbol{a n}$ & $\boldsymbol{b n}$ & $\boldsymbol{c n}$ & $\boldsymbol{d n}$ \\
\hline 1,393243 & 2,234258 & 1 & 1,471217 \\
\hline
\end{tabular}

\subsection{Identifikasi}

Identifikasi pada penelitian ini untuk menentukan sperma sapi normal dan abnormal menggunakan metode jaringan saraf tiruan backpropagation. Jaringan syaraf tiruan terdiri dari lapisan input, hiden layer dan ouput layer. Ditunjukan pada Gambar 5. 
Data dalam penelitian ini terdiri dari 30 citra sperma sapi normal dan 30 sperma sapi abnormal. Proses klasifikasi dilakukan dengan membagi data menjadi dua yaitu training terdiri dari 20 citra sperma sapi normal dan abnormal sedangkan testing terdiri dari 10 citra sperma sapi normal dan abnormal. Parameter yang digunakan untuk melatih klasifikasi sperma sapi normal dan abnormal terdiri 10 hidden layer 1, 5 hidden layer 2, iterasi 1000, dan momentum 0.3. fungsi aktivasi yang digunakan adalah tansig, logsig dan purelin.

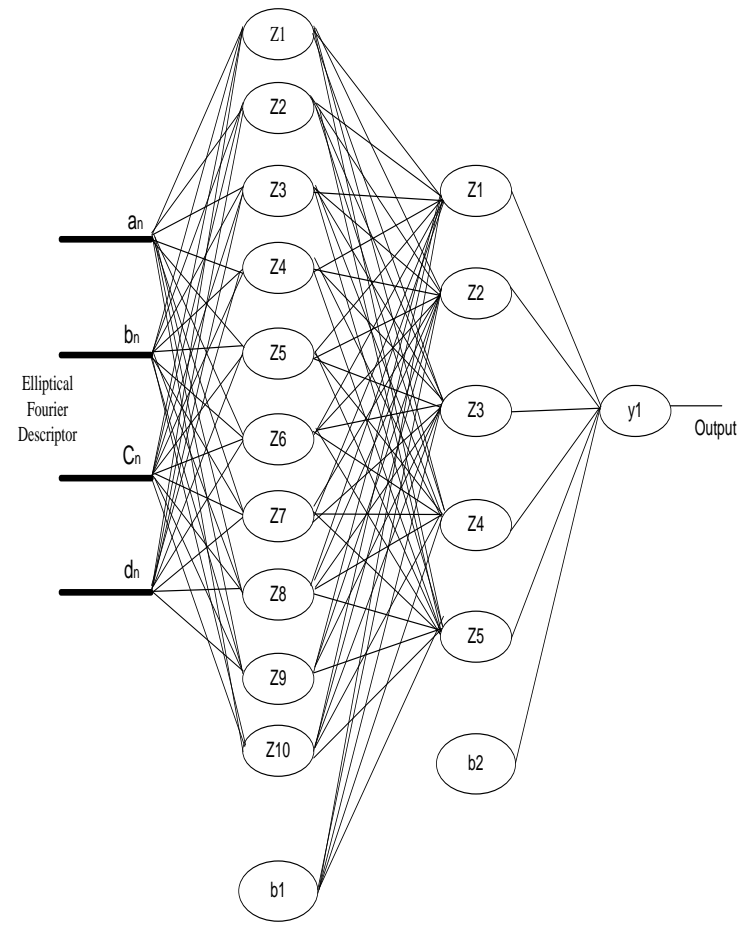

Gambar 5. Arsitektur jaringan

Identifikasi spermatozoa normal dan abnormal dilakukan dengan membandingkan hasil terbaik yang dihasilkan mesin berdasarkan pada jumlah harmonik Fourier. Berdasarkan hasil tersebut didapatkan akurasi identifikasi terbaik pada saat harmonik Fourier sama dengan 6 ditunjukkan pada Tabel 2.

Tabel 2. Akurasi Identifikasi

\begin{tabular}{cc}
\hline Jumlah $N$ & Akurasi (\%) \\
\hline 2 & $63,33 \%$ \\
3 & $65 \%$ \\
4 & $63,33 \%$ \\
5 & $61,67 \%$ \\
6 & $80 \%$ \\
7 & $46.67 \%$ \\
8 & $58,33 \%$ \\
9 & $55 \%$ \\
10 & 56,675 \\
16 & $43,33 \%$ \\
32 & $35 \%$ \\
\hline
\end{tabular}

Pengujian kesatu adalah pengujian dengan sperma sapi dari data citra 21 s.d. 30. Hasil dari pengujian ini dapat dilihat pada Gambar 6. 


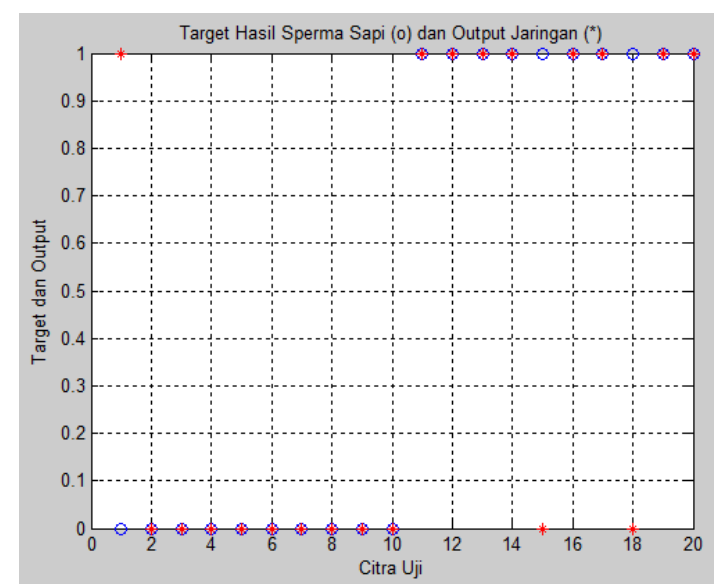

Gambar 6. Hasil pengujian 1

Efektifitas sistem pada pengujian pertama untuk pengenalan sperma sapi normal dan abnormal didapat untuk nilai sensitivity sebesar 0.85 , nilai specificity sebesar 0.15 , dan nilai accuracy sebesar $85 \%$. Pengujian kedua adalah pengujian dengan sperma sapi dari data citra 1 s.d. 10. Hasil dari pengujian ini dapat dilihat pada Gambar 7

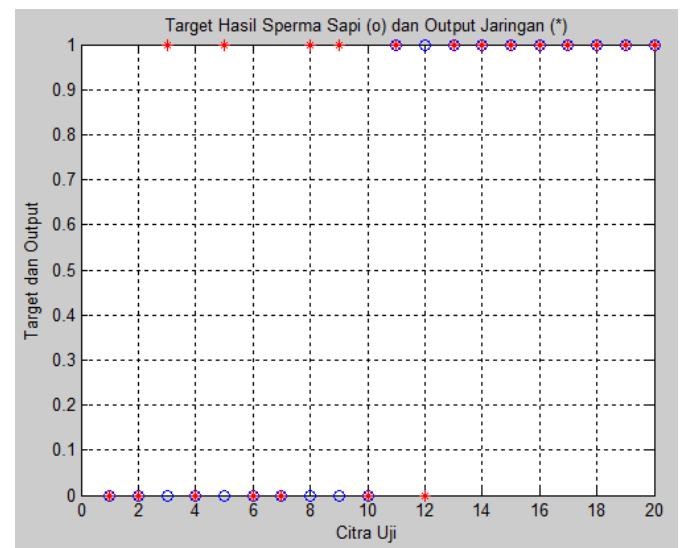

Gambar 7. Hasil pengujian 2

Efektifitas system pengujian kedua untuk pengenalan sperma sapi normal dan abnormal didapat untuk nilai sensitivity sebesar 0.75 , nilai specificity sebesar 0.25 , dan nilai accuracy sebesar $75 \%$. Pengujian ketiga adalah pengujian dengan sperma sapi dari data citra 11 s.d. 20. Hasil dari pengujian ini dapat dilihat pada Gambar 8

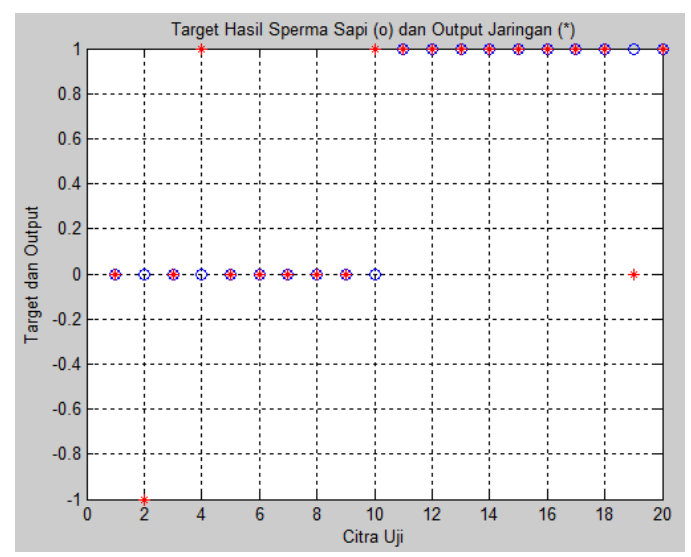

Gambar 8. Hasil pengujian 3

Efektifitas sistem pengujian ketiga untuk pengenalan sperma sapi normal dan abnormal didapat untuk nilai sensitivity sebesar 0.8 , nilai specificity sebesar 0.2 dan nilai accuracy sebesar $80 \%$. 
Tabel 3. Akurasi sistem data pengujian 1-3

\begin{tabular}{cc}
\hline & Accuracy Sperma Sapi \\
\hline Pengujian 1 & $\mathbf{8 5 \%}$ \\
Pengujian 2 & $75 \%$ \\
Pengujian 3 & $\mathbf{8 0 \%}$ \\
Rata-Rata & $\mathbf{8 0 . 0 0 \%}$ \\
\hline
\end{tabular}

Dari (Tabel 3) terlihat hasil keakurasian data dari ke 3 kali pengujian masing-masing jenis sperma sapi normal dan abnormal adalah $80.00 \%$. Ada banyak faktor yang mempengaruhi tingkat keakuratan pada saat identifikasi dilakukan. Mulai dari sempel, ektraksi digunakan maupu proses pelatihan pada jaringan saraf tiruan dengan belum ditemykan cara terbaik untuk memprentasikan data input, mimilih arsitektur serta jumlah node dan jumlah lapisan. ini berpengaruh pada proses selanjutnya. Cara yang digunakan hingga saat ini masih dengan cara coba-coba (trail and error).

\subsection{Tampilan GUI Klasifikasi Sperma Sapi}

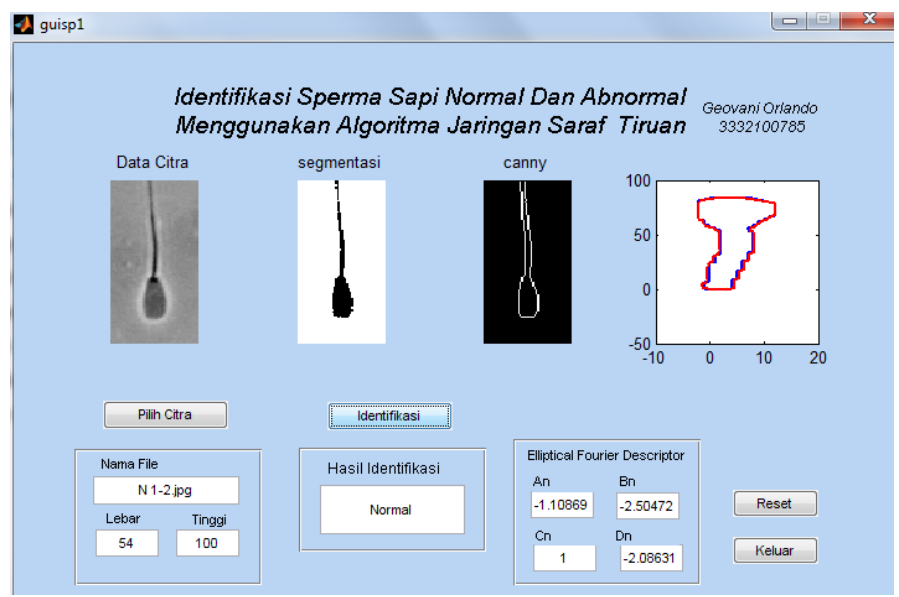

Gambar 9. Tampilan GUI sperma normal

Tampilan awal dari GUI untuk pengenalan sperma sapi normal dan abnomal, terdapat beberapa pushbutton, diantaranya adalah pushbutton untuk mengambil (pilih citra) citra untuk menampilkan citra yang diklasifikasi, pushbutton reset yaitu untuk me-reset dari awal semua proses yang telah dilakukan, pushbutton identifikasi untuk mengidentifikasi citra ke dalam kelas masing-masing normal atau abnormal dan pushbutton keluar digunakan untuk user keluar dari GUI sperma sapi tersebut. Tapilan GUI proses pengujian terdapat kolom rincian dan kolom hasil perhitungan ditunjukan pada Gambar 9.

\section{KESIMPULAN}

Penelitian ini menggunakan fitur bentuk morfologi dalam melakukan identifikasi sperma sapi normal dan abnormal. Hasil terbaik yang dicapai dalam melakukan identifikasi menggunakan algoritma jaringan saraf tiruan metode backpropagation diperoleh pada harmonik fourier sama dengan $6(\mathrm{~N}=6)$. Dengan demikian sistem yang dibangun telah mampu mengidentifikasi sperma sapi normal dan abnormal dengan akurasi sebesar $80 \%$.

\section{DAFTAR PUSTAKA}

[1] Stevanus H, I Ketut EP, Adhi DW, Mira CK, Budi S, Munawir, Slamet H, I Nyoman TA, Dian R, Lukman A. Determining The Abnormality of Bull Tail Morphology Using Support Vector.2013. Vol.7, No.2.

[2] P. Memmolo, G. Di Caprio, C. Distante, M. Paturzo, R. Puglisi, D. Balduzzi, A. Galli, G. Coppola, and P. Ferraro. Identification of Bovine Sperm Head For Morphometry Analysis in Quatitative Phase-contrast Holographic Microscopy.2011.OSA. Vol 19, No.23.

[3] Michael J, Craig D, Nathan E. Cody C. Understanding Bull breading Soundness Evaluations. 
[4] Abbiramy VS, Shanthi V. Spermatozoa Segmentation and Morphological Parameter Analysis Based Detection of Teratoxoospermia. International Journal of Computer. 2010. Vol 3, No.7.

[5] Winarno, K.E. Purnama, S. Hardiristanto, Mauridhi HP. Klasifikasi Spermatozoa Normal dan Abnormal Menggunakan Backpropagation neural Network. 2012. Seminar Nasional Pascasarjana ITS.

[6] Mohd FA, Nor Ashidi MI, Siti AS, Kamal ZZ. Detection of Sprague Dawley Sperm Using Matching Method. University Science Malyasia.

[7] ANS 3319C Reproductive Physiology \& Endocrinology Lab: Semen Evaluation and Cryopreservation: Bovine \& Eguine.

[8] Apriyanti, Cici. Pengaruh Waktu Ekuilibrasi Terhadap Kualitas Semen beku Sapi Pesisir Pre Dan Post Thawing. 2012. Laporan Tesis : Unand.

[9] Prasetyo, Eko. "Pengolahan Citra Digital dan Aplikasinya Menggunakan Matlab". 2011. Penertbit ANDI. Yogyakarta.

[10] Alias, Mohd Fauzi Bin. "Pengklasifikasian Sperma Normal Dan Abnormal Dari Pada Suspensi Sperma Tikus Sprague Dawley”.2009. Laporan Tesis: USM

[11] Jun Liu, Clement Leung, Zhe Lu, Yu Sun. "Quantitative Analysis of Locomotive Behaviorof Human Sperm Head and Tail. 2013. Vol. 60, No. 2

[12] James Bearden, Irwin J Bendet. “Birefringence of Spermatozoa”. 1972. Vol. 55, hal. 459-500

[13] Image Processing Toolbox User's Guide Matlab R2008a.

[14] Muhammad R, R. Iis Arifiantini, Bambang P. "Korelasi Morfologi Abnormalitas Primer Spermatozoa Terhadap Umur Pada Beberapa Bangsa Sapi Potong”. 2012. Vol. 19, No.2 